\title{
Molecular characterization of polar heteroatom species in oilsands bitumen-derived vacuum residue fractions by Fourier transform ion cyclotron resonance mass spectrometry
}

\author{
Fang Zheng ${ }^{1} \cdot$ Warren Chung $^{2} \cdot$ Eusebio Palmisano $^{3} \cdot$ Dahai Dong $^{3} \cdot$ Quan Shi $^{1} \cdot$ Zhiming Xu $^{1} \cdot$ Keng H. Chung $^{4}$
}

Received: 10 June 2018 / Published online: 28 June 2019

(c) The Author(s) 2019

\begin{abstract}
A Canadian in situ oilsands bitumen-derived vacuum residue (VR) was subjected to supercritical fluid extraction and fractionation (SFEF) into 13 extractable fractions and an unextractable end-cut and characterized by positive- and negative-ion electrospray ionization (ESI) Fourier transform ion cyclotron resonance mass spectrometry (FT-ICR MS). The results of negative-ion ESI FT-ICR MS showed that the $\mathrm{N}_{1}$ class species was the most abundant and the multifunctional group compounds, such as $\mathrm{N}_{1} \mathrm{O}_{1}, \mathrm{~N}_{1} \mathrm{O}_{2}, \mathrm{~N}_{1} \mathrm{~S}_{1}, \mathrm{~N}_{1} \mathrm{~S}_{2}$, and $\mathrm{N}_{2}$ class species became abundant as the SFEF fraction became heavier. In positive-ion ESI mode, the relative abundance of $\mathrm{N}_{1}$ class species decreased gradually in the heavy SFEF fractions while that of multifunctional group compounds increased. The relative abundance of $\mathrm{N}_{4} \mathrm{~V}_{1} \mathrm{O}_{1}$ increased dramatically in heavy fractions and the end-cut. The distributions of polar heteroatom species of VR derived from oilsands bitumen were similar with those of VR derived from the Venezuela Orinoco extra heavy oil.
\end{abstract}

Keywords Molecular characterization · Canadian oilsands bitumen $\cdot$ SFEF $\cdot$ ESI $\cdot$ FT-ICR MS

\section{Introduction}

Canadian oilsands bitumen and Venezuela extra heavy oil are the world's largest reserves and are strategically important to meet the growing demand of petroleum (Demirbas et al. 2016; Zhou et al. 2008). The characteristics of these two feedstocks are that they contain considerable amounts of vacuum residue (VR) and asphaltenes, as well as high concentrations of heteroatoms, such as sulfur, nitrogen, oxygen, and metals, which make them difficult to process in refining operation. (Chen et al. 2015; Ortega et al. 2015; Wei et al. 2015; Yin et al. 2013) (Gao et al. 2013; Subramanian

Edited by Xiu-Qin Zhu and Xiu-Qiu Peng

Keng H. Chung

kengchung@hotmail.com

1 State Key Laboratory of Heavy Oil Processing, China University of Petroleum, Beijing 102249, China

2 Well Resources Inc, Edmonton, Canada

3 Cenovus Energy Inc, Calgary, Canada

4 Qingdao Institute of Bioenergy and Bioprocess Technology, Chinese Academy of Sciences, Qingdao 266101, China and Hanson 1998). The common industry practice is to use energy intensive and costly pretreatment technologies such as coking and ebullated-bed hydroprocessing to remove heteroatoms and metals. The products from these processes require further processing to produce clean transportation fuels that meet stringent environment regulations (Gulyaeva et al. 2017; Ng et al. 2015; Zaikin and Zaikina 2016; Zhang et al. 2017).

A recent study showed that if the asphaltenes were selectively removed from the VR, the deasphalted residue can be processed in conventional packed hydroprocessing units (Yuan et al. 2016; Zachariah and de Klerk 2017). This will reduce energy intensity of residue processing by eliminating the use of less energy efficient and costly coking and ebullated-bed reactor systems for feedstock pretreatment (Cheng et al. 2009; Morimoto et al. 2010; Rose et al. 2001). Zhang et al. (2013) studied the transformation of nitrogen compounds in deasphalted VR derived from a Chinese Liaohe crude and a Venezuela Orinoco extra heavy oil during catalytic hydrotreating. Fourier transform ion cyclotron resonance mass spectrometry (FT-ICR MS) was used to analyze the feed and product before and after the hydrotreating and concluded that a significant difference in nitrogen removal for the deasphalted VR was due to the structural variation of 
the neutral nitrogen compounds. The easy-to-convert nitrogen compounds had less and/or shorter alkyl side chains than the hard-to-convert nitrogen compounds which had long alkyl side chains. Therefore, a better understanding of the chemistry of heavy petroleum fractions will allow refiners to select the appropriate VR processing scheme, as well as to optimize the process operating parameters (Sato et al. 2010; Scott et al. 2001; Xu et al. 2007).

Heavy petroleum fractions are mixtures comprising millions of ill-defined complex hydrocarbon compounds. The chemistry of petroleum residuum is difficult to define, due to the lack of adequate analytical techniques for characterizing heavy petroleum fractions. As a result, it is impossible to correlate feedstock properties of residuum to its reaction process performance. Recently, a comprehensive residue characterization method was developed, which combines the use of supercritical fluid extraction and fraction (SFEF) followed by FT-ICR MS (Banerjee 2011; Liu et al. 2015). The SFEF is a solvent separation process which fractionates VR into multiple narrow fractions, based on the solubility and molecular weight of VR components (Chung et al. 1997; Yang and Wang 1999; Zhao et al. 2018). The FT-ICR MS is an ultrahigh-resolution mass spectrometry which provides a nondestructive molecular characterization of complex hydrocarbon systems (Rodgers et al. 2001; Shi et al. 2008; Wang et al. 2013; Yahe et al. 2015).

This paper provides molecular compositions of oilsands bitumen-derived VR fractions and compares with those of Venezuela extra heavy oil-derived VR.

\section{Materials and methods}

\subsection{Materials}

The oilsands bitumen was obtained from a commercial in situ operation in Northern Alberta and subjected to pilotscale vacuum distillation to yield a distillate and $500{ }^{\circ} \mathrm{C}^{+} \mathrm{VR}$ fraction. The VR was further fractionated into 13 extractable narrow fractions and an unextractable end-cut by SFEF using pentane solvent. The experimental setup and operating procedure of SFEF have been described elsewhere (Chung et al. 1997; Zhang et al. 2012a). Analytical reagent grade solvents, toluene and methanol were purified by distillation, prior to use in preparing samples for analyses.

\subsection{ESI FT-ICR MS analysis}

The SFEF fraction $(10 \mathrm{mg})$ was mixed with $1 \mathrm{~mL}$ of toluene. The mixture solution $(20 \mu \mathrm{L})$ was diluted with $1 \mathrm{~mL}$ of toluene/methanol (1:3) solution, followed by adding 15 $\mu \mathrm{L}$ of an aqueous solution of ammonium hydroxide (28-35 $\mathrm{wt} \%)$ as an ionization promoter for negative-ion ESI.
Correspondingly, $10 \mu \mathrm{L}$ of $\mathrm{HCOOH}$ was added as an ionization promoter for positive-ion ESI. The sample solution was injected via an Apollo II electrospray source at $180 \mu \mathrm{L} / \mathrm{h}$ and analyzed using a Bruker apex-ultra FT-ICR MS equipped with a $9.4 \mathrm{~T}$ superconducting magnet. The operating conditions of negative-ion ESI FT-ICR MS were $4.1 \mathrm{kV}$ spray shield voltage, $4.6 \mathrm{kV}$ capillary column front end voltage and $-320 \mathrm{~V}$ capillary column end voltage. The ions were accumulated in a hexapole for $1 \mathrm{~ms}$. The DC voltage was - 3.0 V with $500 \mathrm{Vpp}$ RF amplitude and $1.2 \mathrm{~ms}$ delay was selected to transfer to the ICR cell. Optimized mass for Q1 was $m / z$ 200. The ions accumulated in Qh-Interface were $2 \mathrm{~s}$ with $5 \mathrm{MHz}$ hexapoles and $500 \mathrm{Vpp} \mathrm{RF}$ amplitude. The ICR cell was $13.5 \mathrm{db}$ attenuation, and 200-1000 Da mass range was selected. The data size set was $4 \mathrm{M}$ with 64 scans co-added, resulting in a resolving power of 400,000 at $\mathrm{m} / \mathrm{z}$ 500. The operating conditions of positive-ion ESI FT-ICR MS were $-3.5 \mathrm{kV}$ spray shield voltage, $-3.0 \mathrm{kV}$ capillary column front end voltage, and $280 \mathrm{~V}$ capillary column end voltage. The ions accumulated in a hexapole for $0.1 \mathrm{~s}$. The DC voltage was $2.0 \mathrm{~V}$ with $350 \mathrm{Vpp}$ RF amplitude and $1.3 \mathrm{~ms}$ delay was selected to transfer to the ICR cell. Optimized mass for Q1 was $m / z 200$. The ion accumulated in Qh-Interface was $2 \mathrm{~s}$ with $5 \mathrm{MHz}$ hexapoles and $400 \mathrm{Vpp}$ RF amplitude. The ICR cell was set to $1.3 \mathrm{~ms}$ and $12.1 \mathrm{db}$ attenuation, and 200-1000 Da mass range was selected. The data size set was $4 \mathrm{M}$ with 64 scans co-added, resulting in a resolving power of 400,000 at $\mathrm{m} / \mathrm{z} 500$.

\subsection{Mass calibration and data analysis}

The mass spectrum peaks were calibrated using a crude oil, and the mass errors were less than $1 \mathrm{ppm}$. Internal calibration was carried out using the identified homologous series of $\mathrm{N}_{1}$ compounds. Peaks with relative abundance greater than five times the standard deviation of the baseline noise were selected and analyzed using the in-house software, which has been described elsewhere (Shi et al. 2013). Species with the same heteroatom class and its isotopes with different double-bond equivalent (DBE) values and carbon numbers were searched within a set \pm 0.001 Kendrick mass defect (KMD) tolerance (Shi et al. 2013).

\section{Results and discussion}

\subsection{Properties of VR and its SFEF fractions}

Table 1 shows the properties of oilsand-derived VR and its SFEF fractions. The extractable SFEF fractions accounted for $67 \mathrm{wt} \%$ of VR. The molecular weight (MW) of extractable SFEF fractions increased from 500 to $1000 \mathrm{Da}$. The unextractable end-cut with high molecular weight of 


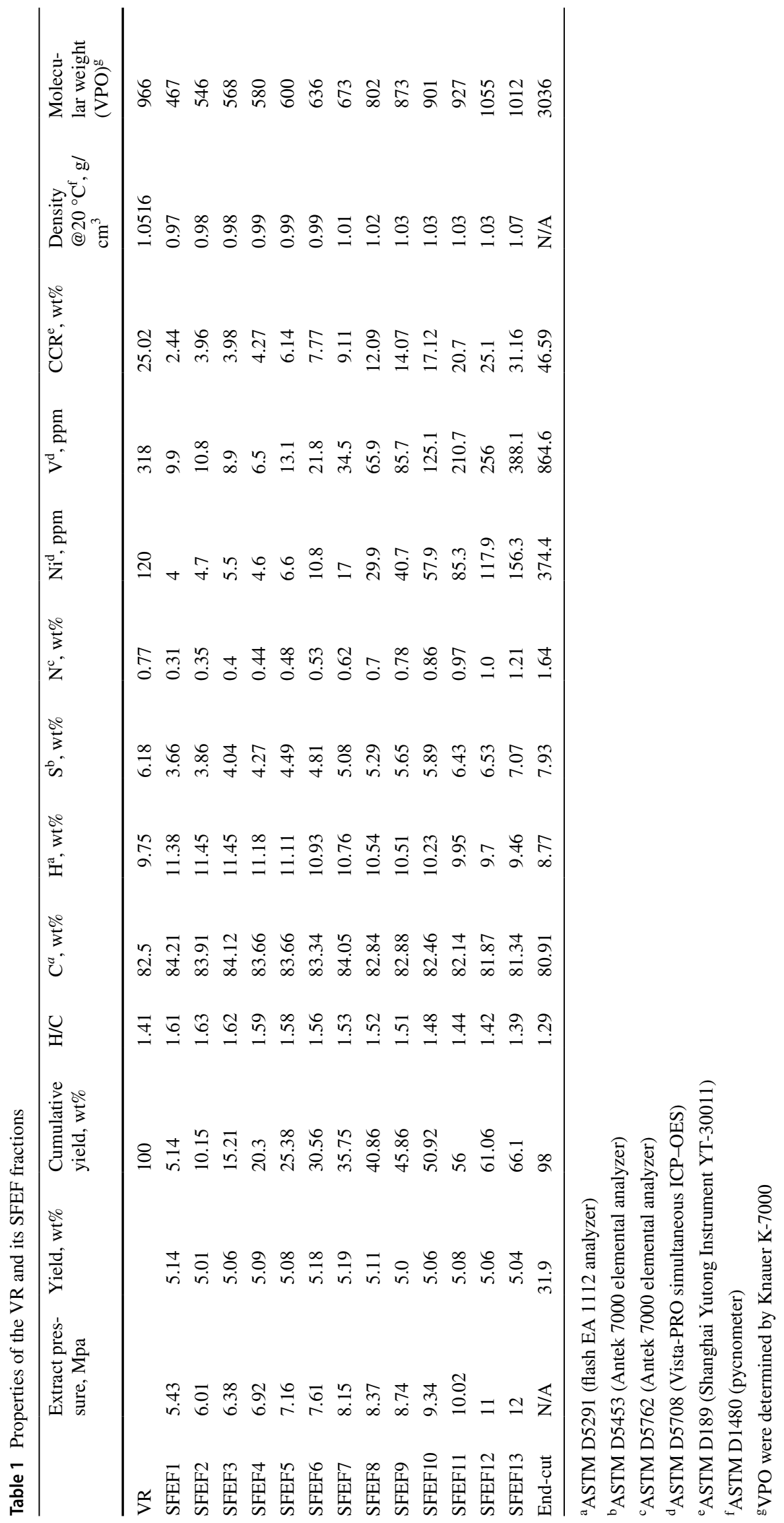


$3000 \mathrm{Da}$ determined by vapor pressure osmometry is likely due to molecular aggregation. (Zhang et al. 2014) As the SFEF fraction became heavier, the hydrogen-to-carbon $(\mathrm{H} / \mathrm{C})$ ratio of SFEF fraction decreased, and the density, sulfur, nitrogen, Conradson carbon residue (CCR) and metals contents increased.

The bulk vanadium concentration of VR was very high at $318 \mathrm{wppm}$. In the SFEF fractions, the vanadium concentration increased gradually in the extractable SFEF fractions; 9.9 wppm in SFEF1, 211 wppm in SFEF11, 388 wppm in SFEF13, and increased abruptly to 865 wppm in the unextractable end-cut. The trend of nickel concentrations in SFEF fractions was similar to that of vanadium. In general, the properties of VR and its SFEF fractions were similar to

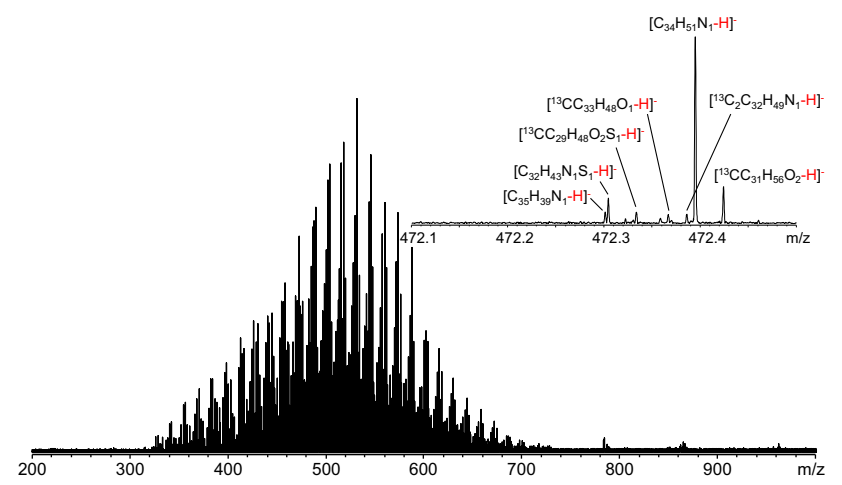

Fig. 1 Negative-ion ESI FT-ICR MS broadband spectrum of SFEF fraction SFEF1. The insert is the expanded mass spectrum at $\mathrm{m} / z, 472$ those reported for mined oilsand-derived VR (Chung et al. 1997).

\subsection{Molecular composition characterized by negative-ion ESI FT-ICR MS}

Figure 1 shows the negative-ion ESI FT-ICR MS broadband spectrum of fraction SFEF1 at $m / z 200-1000$. The insert is the close-up view of expanded mass spectrum at $m / z, 472$ (randomly selected for illustration purposes) which shows a mass resolution power of 300,000. The high-resolution mass spectrum provides distinct assignments of compounds with unique elemental compositions. The even-mass peaks at $\mathrm{m} / \mathrm{z}$ 450-700 indicated that the dominant compounds were $\mathrm{O}_{2}$ and $\mathrm{N}_{1}$ class species.

Figure 2 shows the negative-ion ESI FT-ICR MS broadband spectra of various SFEF fractions. The abundant peaks were located at $m / z$ 400-600 range. As the SFEF fraction became heavier, the mass distribution range shifted slightly to the right. The mass spectrum of the nonextractable SFEF end-cut was distinctly different from those of extractable SFEF fractions (SFEF 1-13). Low peak intensities indicated that high molecular weight species in the SFEF end-cut were insufficiently ionized. The signal intensities of extractable SFEF fractions also showed that ionization efficiency decreased slightly as the SFEF fraction became heavier.

Figure 3 shows the close-up view of expanded mass spectra of various SFEF fractions at $\mathrm{m} / \mathrm{z} 472$. The differences in molecular composition among the SFEF fractions were distinct, indicating the effectiveness of SFEF in separating VR into multiple narrow
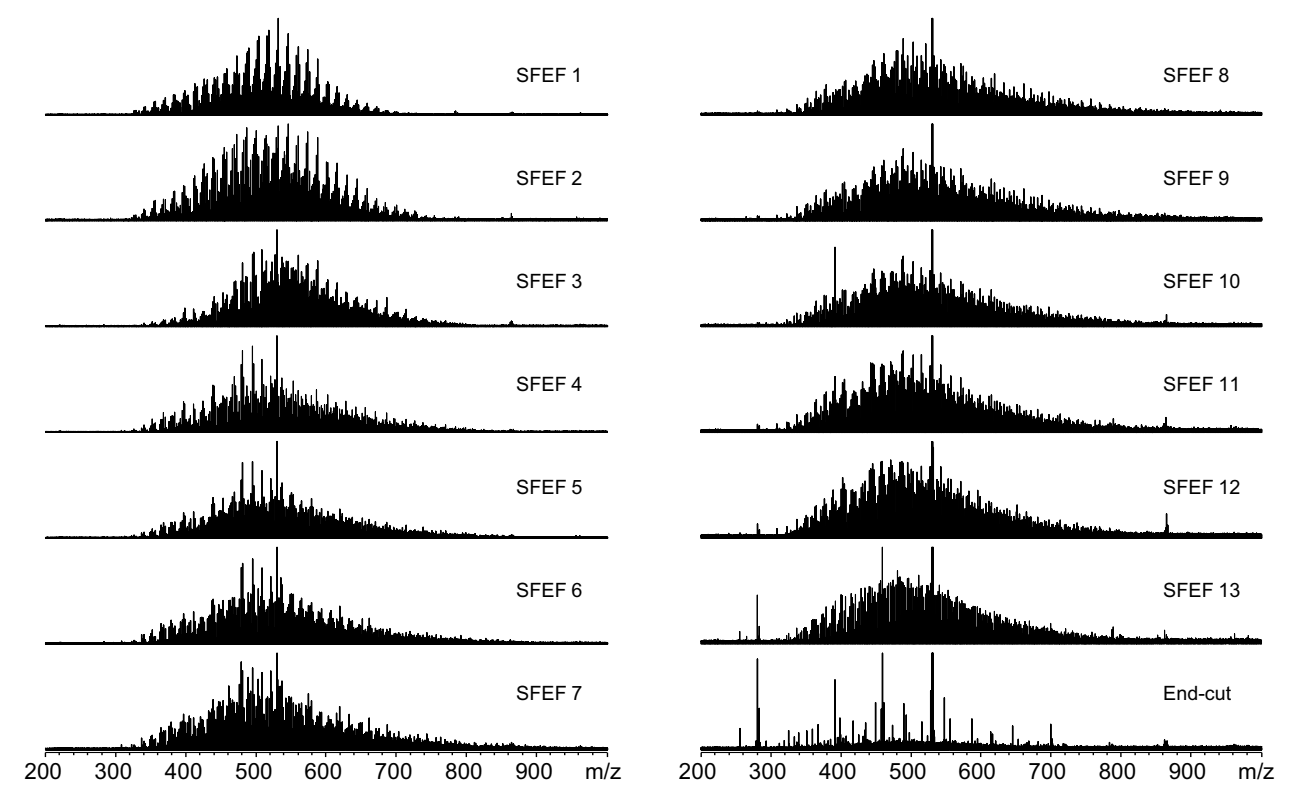

Fig. 2 Negative-ion ESI FT-ICR MS broadband spectra of various SFEF fractions 

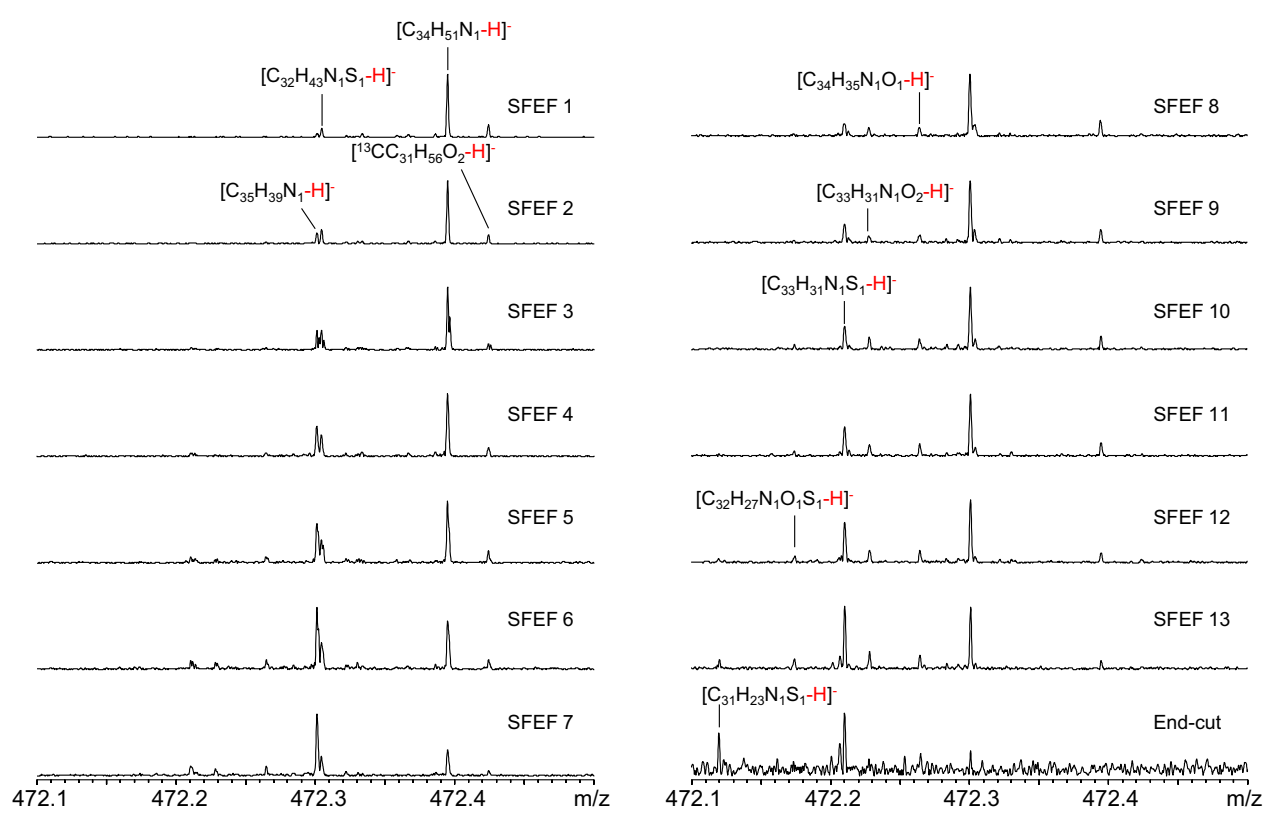

Fig. 3 Expanded negative-ion ESI FT-ICR MS spectra of various SFEF fractions at $\mathrm{m} / \mathrm{z} 472$

fractions. In SFEF1, $\left[\mathrm{C}_{34} \mathrm{H}_{51} \mathrm{~N}_{1}-\mathrm{H}\right]^{-}$with 10 DBEs was the most abundant, followed by $\left.\mathrm{C}_{32} \mathrm{H}_{43} \mathrm{~N}_{1} \mathrm{~S}_{1}-\mathrm{H}\right]^{-}$and $\left[\mathrm{C}_{35} \mathrm{H}_{39} \mathrm{~N}_{1}-\mathrm{H}\right]^{-}$with 17 DBEs. However, the abundance of $\left[\mathrm{C}_{34} \mathrm{H}_{51} \mathrm{~N}_{1}-\mathrm{H}\right]^{-}$decreased dramatically in heavier SFEF fractions and was substituted by $\left[\mathrm{C}_{35} \mathrm{H}_{39} \mathrm{~N}_{1}-\mathrm{H}\right]^{-}$, indicating that heavy SFEF fractions were more aromatic. The abundances of $\left[\mathrm{C}_{34} \mathrm{H}_{35} \mathrm{~N}_{1} \mathrm{O}_{1}-\mathrm{H}\right]^{-},\left[\mathrm{C}_{33} \mathrm{H}_{31} \mathrm{~N}_{1} \mathrm{O}_{2}-\mathrm{H}\right]^{-}$, $\left[\mathrm{C}_{33} \mathrm{H}_{31} \mathrm{~N}_{1} \mathrm{~S}_{1}-\mathrm{H}\right]^{-}$and $\left[\mathrm{C}_{32} \mathrm{H}_{27} \mathrm{~N}_{1} \mathrm{O}_{1} \mathrm{~S}_{1}-\mathrm{H}\right]^{-}$increased in the heavier SFEF fractions, indicating that the relative abundance of the multifunctional group class, such as $\mathrm{N}_{1} \mathrm{O}_{1}$, $\mathrm{N}_{1} \mathrm{O}_{2}, \mathrm{~N}_{1} \mathrm{~S}_{1}$, and $\mathrm{N}_{1} \mathrm{O}_{1} \mathrm{~S}_{1}$ increased as the SFEF fraction became heavier.

Figure 4 shows the relative ion abundance plots of DBE as a function of carbon number for pyrrolic compounds $\left(\mathrm{N}_{1}\right.$-class species) in various SFEF fractions. The dots in the plots denote the abundance of species. Pyrrolic compounds can be easily ionized by negative-ion ESI. Data in Fig. 4 showed that the distribution of pyrrolic compounds shifted diagonally to top-right, indicating that the pyrrolic compounds in heavier SFEF fractions were larger (higher carbon numbers) and more condensed (higher DBE values) molecules. The most abundant pyrrolic compounds in SFEF1 had 10 DBEs and 33 carbons, whereas those in SFEF13 had 20 DBEs and 37 carbons. Even though SFEF end-cut was insufficiently ionized, the data in Fig. 4 showed that the pyrrolic compounds in SFEF end-cut were the homologous pyrrolic compounds as found in the extractable SFEF fractions, but with higher DBEs and carbon numbers.
Figure 5 shows the relative ion abundance plots of DBE as a function of carbon number for $\mathrm{O}_{2}$-class species in various SFEF fractions. Compared to data in Fig. 4, the trend of distribution of $\mathrm{O}_{2}$-class species in the SFEF fractions was different from that of pyrrolic compounds. The $\mathrm{O}_{2}$-class species in SFEF fractions were centered at 30-40 carbon numbers and their DBE increased as SFEF fraction became heavier, indicating a vertical shift in distribution of $\mathrm{O}_{2}$-class species in heavier SFEF fractions.

The DBE variation of $\mathrm{O}_{2}$-class species in SFEF fractions was inconspicuous, since the number of naphthenic rings has relatively low impact on the polarity of a molecule as compared to aromatic rings. As for the end-cut, the series with $1 \mathrm{DBE}$ was corresponding to fatty acids which were contaminants commonly found in negative-ion ESI analysis.

Figure 6 shows the relative abundance of heteroatom class species in various SFEF fractions by negative-ion ESI FT-ICR MS. Twelve class species were assigned, namely $\mathrm{N}_{1}$, $\mathrm{N}_{1} \mathrm{O}_{1}, \mathrm{~N}_{1} \mathrm{O}_{2}, \mathrm{~N}_{1} \mathrm{~S}_{1}, \mathrm{~N}_{1} \mathrm{~S}_{2}, \mathrm{~N}_{2}, \mathrm{O}_{1}, \mathrm{O}_{1} \mathrm{~S}_{1}, \mathrm{O}_{2}, \mathrm{O}_{2} \mathrm{~S}_{1}, \mathrm{O}_{2} \mathrm{~S}_{2}$, and $\mathrm{O}_{3}$. Among them, $\mathrm{N}_{1}$ class species were the most abundant. The abundances of multifunctional group compounds, such as $\mathrm{N}_{1} \mathrm{O}_{1}, \mathrm{~N}_{1} \mathrm{O}_{2}, \mathrm{~N}_{1} \mathrm{~S}_{1}, \mathrm{~N}_{1} \mathrm{~S}_{2}$, and $\mathrm{N}_{2}$ class species, increased as the fraction became heavier.

\subsection{Molecular composition characterized by positive-ion ESI FT-ICR MS}

Figure 7 shows the positive-ion ESI FT-ICR MS spectra of various SFEF fractions. Basic compounds, such as pyridines, 

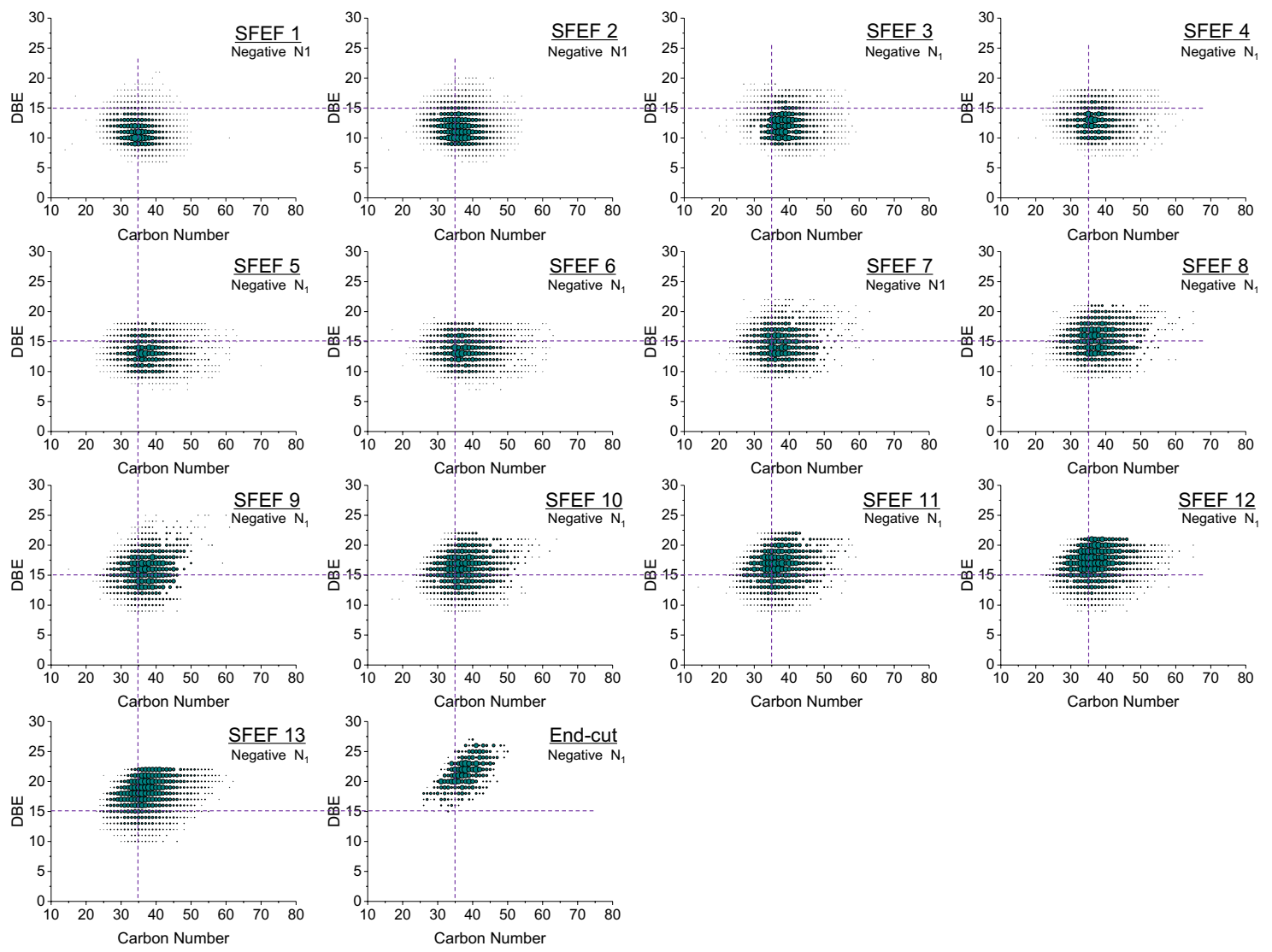

Fig. 4 Relative ion abundance plots of DBE as a function of carbon number derived from negative-ion ESI FT-ICR mass spectra for $\mathrm{N}_{1}$ class species (pyrrolic compounds) in various SFEF fractions

sulfoxides, and metal porphyrin compounds, can be ionized by positive-ion ESI. As the SFEF fraction became heavier, the mass distribution range of mass spectra shifted slightly to the right. The mass peaks of SFEF12, SFEF13, and endcut were sparse. This could be due to the low ionization efficiency or suppressed by the high responses of vanadyl porphyrins. The most abundant peaks at $m / z, 450-700$ in SFEF12, SFEF13, and end-cut were vanadium compounds. More detailed discussion on these compounds will be in the following section.

Figure 8 shows the expanded mass spectra of various SFEF fractions at $m / z 542$. The differences in molecular composition among the SFEF fractions were distinct. The peak of $\left[\mathrm{C}_{39} \mathrm{H}_{59} \mathrm{~N}_{1}+\mathrm{H}\right]^{+}$with 11 DBEs was dominant in the light SFEF fractions, but decreased in the heavy SFEF fractions, and was substituted by $\left[\mathrm{C}_{40} \mathrm{H}_{47} \mathrm{~N}_{1}+\mathrm{H}\right]^{+}$with 18 DBEs in SFEF8, SFEF9, and SFEF10, indicating more highly aromatic compounds in heavier SFEF fractions. In SFEF12, SFEF13, and end-cut, $\left[\mathrm{C}_{32} \mathrm{H}_{34} \mathrm{~N}_{4} \mathrm{O}_{1} \mathrm{~V}_{1}+\mathrm{H}\right]^{+}$was predominant. The relative abundances of multifunctional group class species, such as $\mathrm{N}_{1} \mathrm{O}_{1}, \mathrm{~N}_{1} \mathrm{O}_{2}, \mathrm{~N}_{1} \mathrm{~S}_{1}$, and $\mathrm{N}_{1} \mathrm{~S}_{2}$ increased as SFEF fraction became heavier.

Figure 9 shows the relative ion abundance plots of DBE as a function of carbon number for $\mathrm{N}_{1}$-class species in various $\mathrm{SFEF}$ fractions. The $\mathrm{N}_{1}$-class species, such as pyridine derivative compounds, are basic nitrogen compounds, since amines are rarely present in petroleum crude. The $\mathrm{N}_{1}$-class species in SFEF fractions contained 30-50 carbons. The minimum DBE value for basic nitrogen species in SFEF fractions was 4, which is consistent with DBE value of pyridines. The $\mathrm{N}_{1}$-class species with higher than 4 DBE are likely a pyridine unit attached to naphthenic rings. The size of DBE distribution of $\mathrm{N}_{1}$-class species in SFEF fraction expanded as the SFEF fraction became heavier.

Figure 10 shows the relative ion abundance plots of DBE as a function of carbon number for $\mathrm{N}_{1} \mathrm{~S}_{1}$ class species in various SFEF fractions. The $\mathrm{N}_{1} \mathrm{~S}_{1}$-class species 

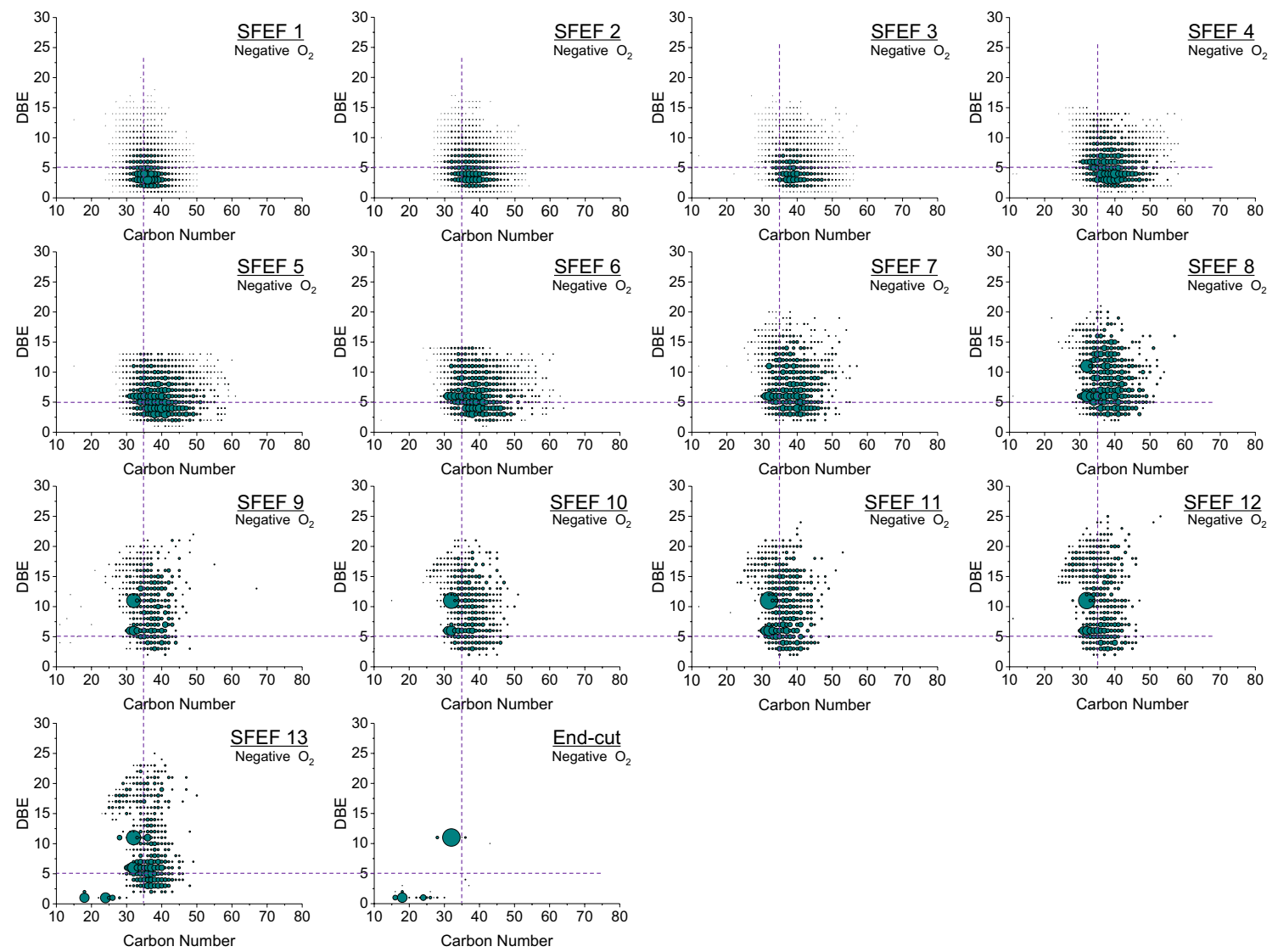

Fig. 5 Relative ion abundance plots of DBE as a function of carbon number derived from negative-ion ESI FT-ICR mass spectra for $\mathrm{O}_{2}$ class species in various SFEF fractions

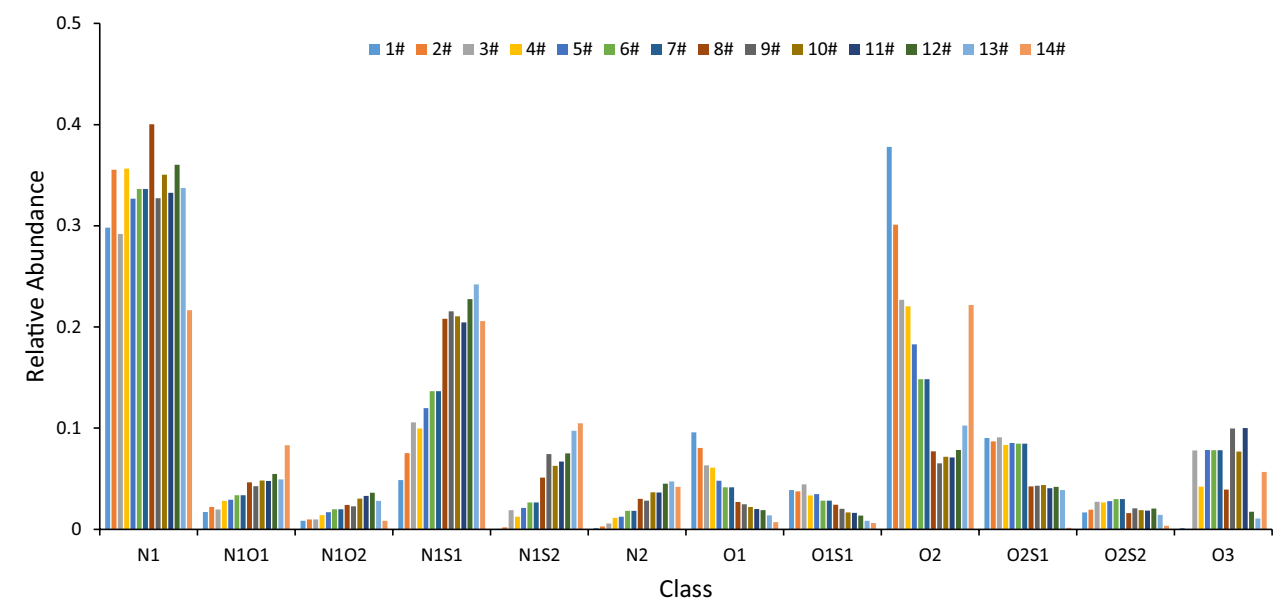

Fig. 6 Relative abundance of heteroatom class species assigned from negative-ion ESI FT-ICR mass spectra of various SFEF fractions

are likely an $\mathrm{N}_{1}$-class species attached to a $\mathrm{S}_{1}$-functional group. The DBE distribution patterns of $\mathrm{N}_{1} \mathrm{~S}_{1}$ class species of SFEF fractions were similar to those of $\mathrm{N}_{1}$-class species shown in Fig. 9. 

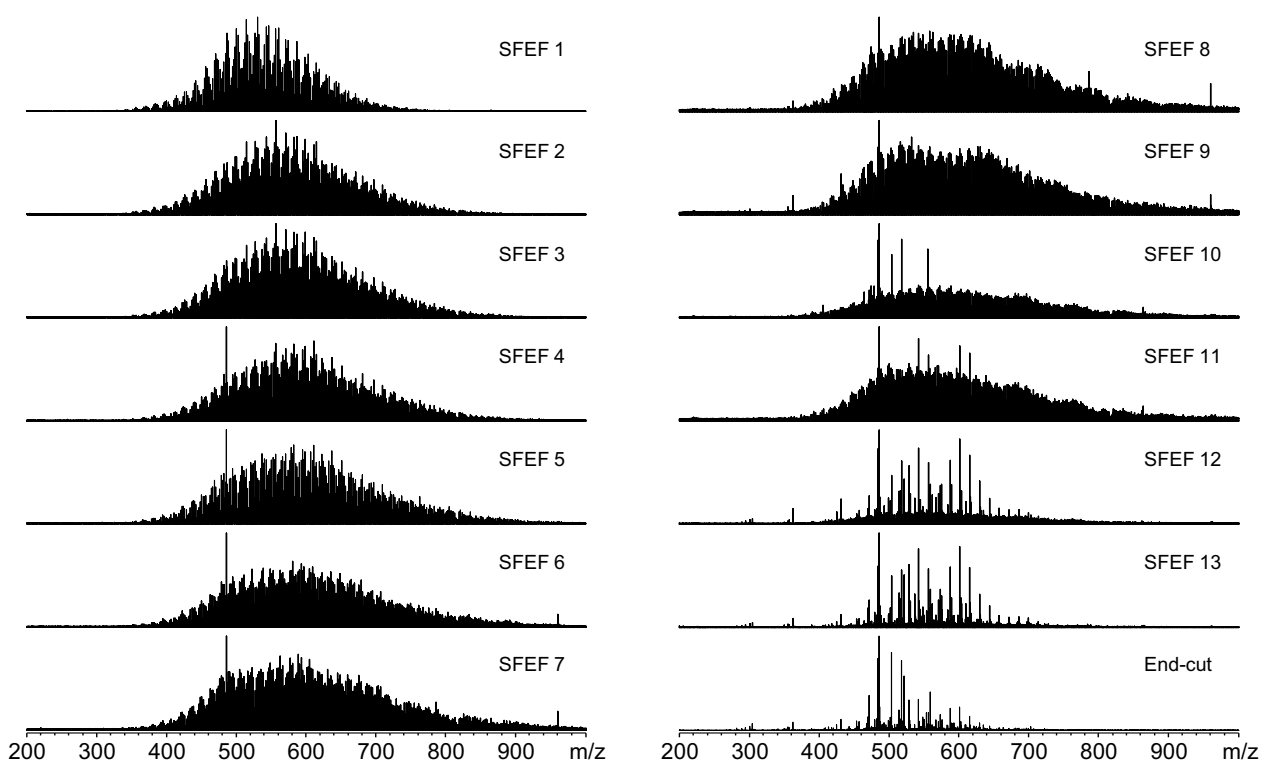

Fig. 7 Broadband positive-ion ESI FT-ICR mass spectra of various SFEF fractions
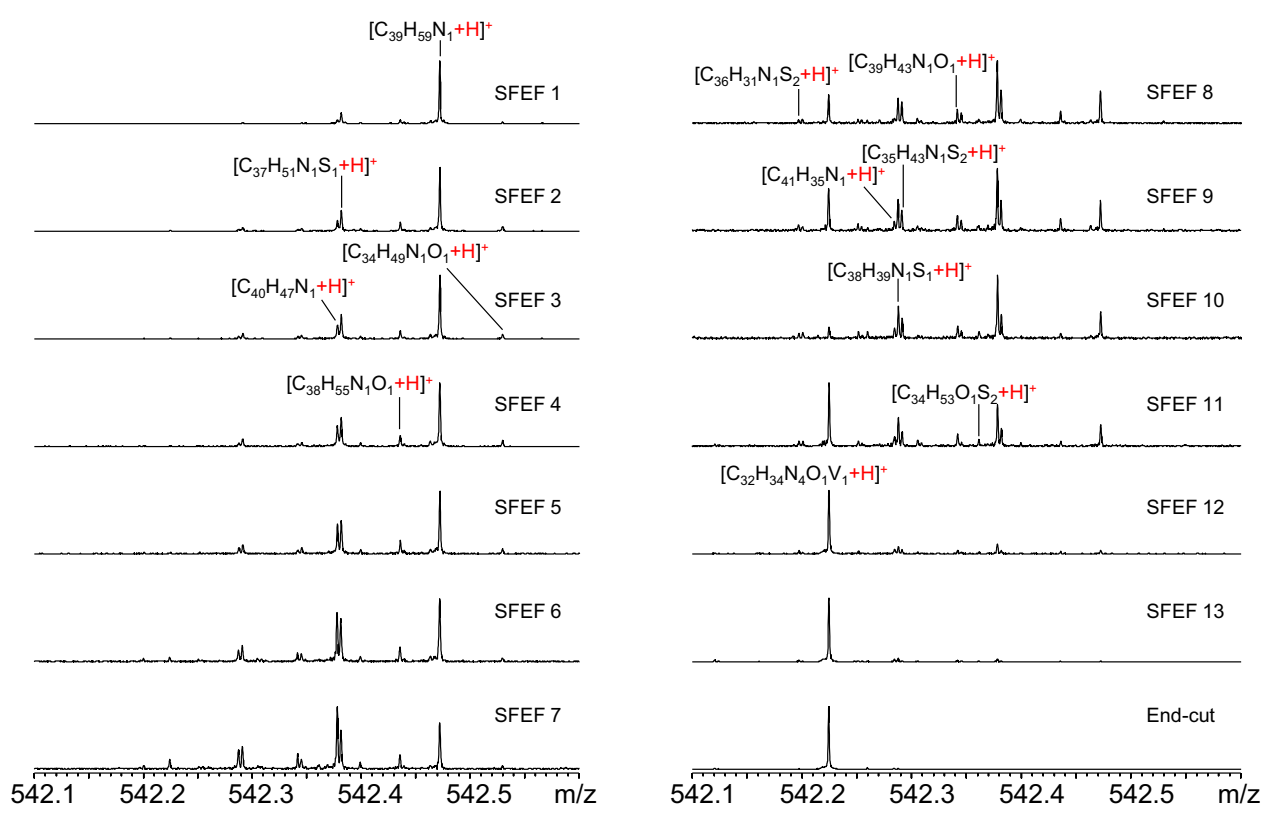

Fig. 8 Expanded positive-ion ESI FT-ICR mass spectra of various SFEF fractions at $\mathrm{m} / z, 542$

Figure 11 shows a total of 12 class species, such as $\mathrm{N}_{1}, \mathrm{~N}_{1} \mathrm{O}_{1}, \mathrm{~N}_{1} \mathrm{O}_{1} \mathrm{~S}_{1}, \mathrm{~N}_{1} \mathrm{O}_{2}, \mathrm{~N}_{1} \mathrm{~S}_{1}, \mathrm{~N}_{1} \mathrm{~S}_{2}, \mathrm{~N}_{2}, \mathrm{~N}_{2} \mathrm{~S}_{1}, \mathrm{~N}_{4} \mathrm{O}_{1} \mathrm{~V}_{1}$, $\mathrm{N}_{5} \mathrm{O}_{1} \mathrm{~V}_{1}, \mathrm{O}_{1} \mathrm{~S}_{1}$, and $\mathrm{O}_{1} \mathrm{~S}_{2}$ compounds, were identified by positive-ion ESI FT-ICR in various SFEF fractions. The relative abundance of $\mathrm{N}_{1}$ class species decreased gradually as the
SFEF fraction became heavier and disappeared in the endcut. Conversely, the relative abundance of $\mathrm{N}_{4} \mathrm{~V}_{1} \mathrm{O}_{1}$ increased dramatically from $0.1 \%$ in SFEF1 to $73 \%$ in SFEF13, and $80 \%$ in the end-cut. 

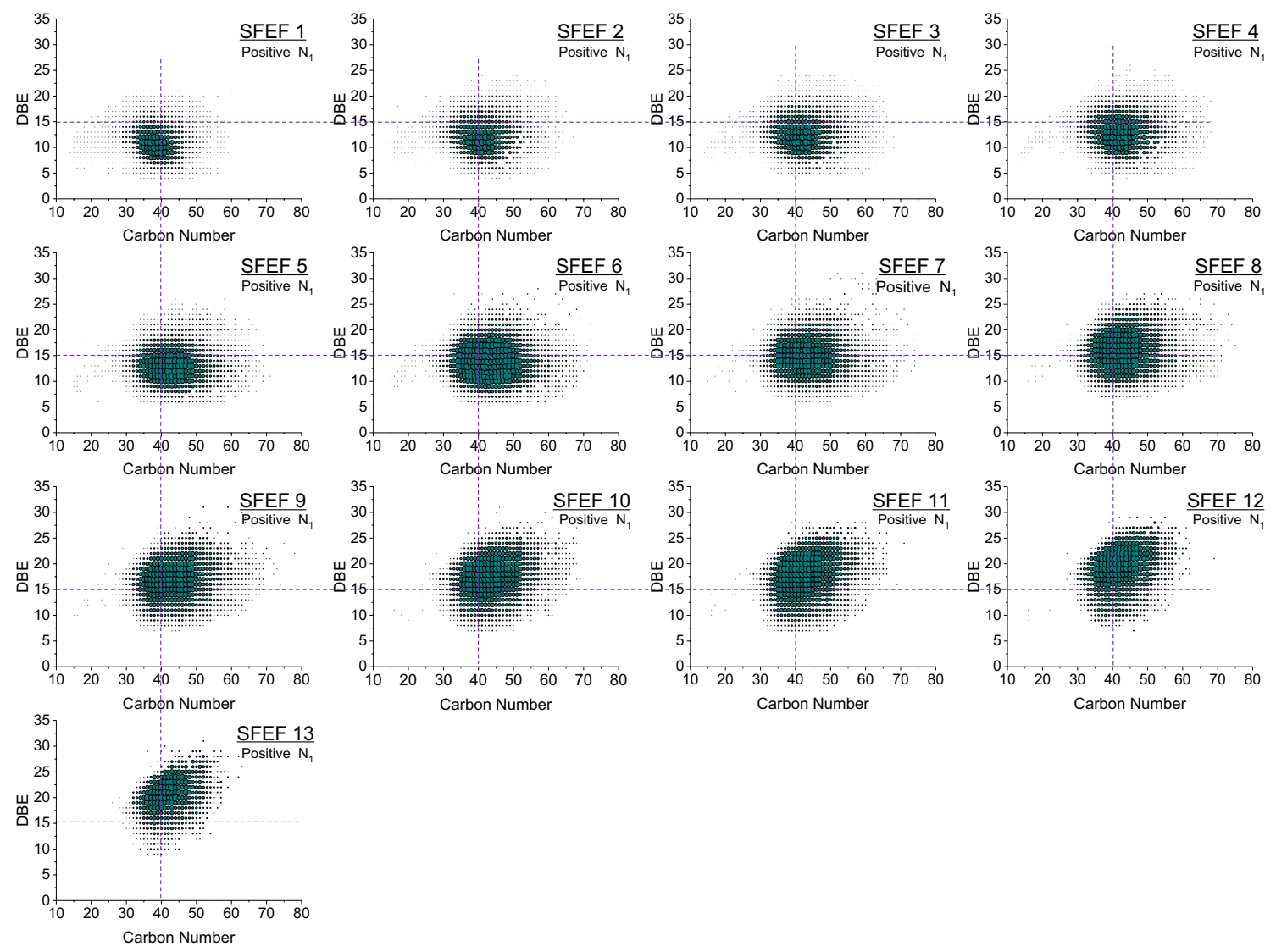

Fig. 9 Relative ion abundance plots of DBE as a function of carbon number derived from positive-ion ESI FT-ICR mass spectra for $\mathrm{N}_{1}$-class species in various SFEF fractions. No $\mathrm{N}_{1}$ compounds were detected in the end-cut

\subsection{Vanadium compounds in SFEF fractions}

Canadian oilsands bitumen contains a high concentration of vanadium which is difficult to process in refining operations. All six-petroleum-derived vanadyl porphyrins, such as ETIO, DPEP, di-DPEP, rhodo-ETIO, rhodo-DPEP, and rhodo-di-DPEP, were detected in SFEF fractions by the accurate mass values identified by positive-ion ESI FT-ICR MS. Figure 12 shows the relative ion abundance plots of DBE as a function of carbon number for $\mathrm{N}_{4} \mathrm{VO}$ compounds in various SFEF fractions. Only a few dots were observed in SFEF1 indicating very low abundance of vanadyl porphyrins and the number of dots increased as the SFEF fraction became heavier. In SFEF1-7, only two types of vanadyl porphyrins (ETIO with 17 DBEs and DPEP with 18 DBEs) were detected. In the heavy SFEF fractions, all six types of petroleum-derived vanadyl porphyrins were detected. The number of carbons in these vanadyl porphyrins varied over a wide range. Most of the peaks in the end-cut were vanadyl porphyrins indicating a high abundance of vanadyl porphyrins, which is consistent with the results shown in Table 1.

\subsection{Comparison of Canadian oilsands bitumen and Venezuela Orinoco extra heavy oil}

The properties of Venezuela Orinoco extra heavy oil closely resemble those of Canadian oilsands bitumen, heavy feedstocks with high concentrations of contaminants. Due to their enormous reserves, these two feedstocks have been studied extensively. Zhang et al.(2012b) conducted a similar molecular characterization study using FT-ICR MS on a $500{ }^{\circ} \mathrm{C}$ Venezuela VR sample (bulk properties: $1.0524 \mathrm{~g} /$ $\mathrm{cm}^{3}$ density at $20{ }^{\circ} \mathrm{C}, 4.8 \mathrm{wt} \%$ sulfur, $0.98 \mathrm{wt} \%$ nitrogen, $176 \mathrm{wppm}$ nickel, and $752 \mathrm{wppm}$ vanadium) and its SFEF narrow fractions. The mass range and maximum peak of the Venezuela SFEF fraction increased as the fraction became heavier, which were different from those of the oilsands bitumen-derived VR. This cannot be explained by their compositional differences, since the FT-ICR MS analysis has poor reproducibility in mass distribution. In the Venezuela VR, the relative abundance of multifunctional group classes, such as $\mathrm{N}_{1} \mathrm{O}_{1}, \mathrm{~N}_{1} \mathrm{O}_{2}, \mathrm{~N}_{1} \mathrm{~S}_{1}$, and $\mathrm{N}_{1} \mathrm{~S}_{2}$ increased gradually as the fraction became heavier. The DBE value and carbon number for pyrrolic compounds in the Venezuela VR-derived SFEF fractions showed progressive changes. However, the DBE 

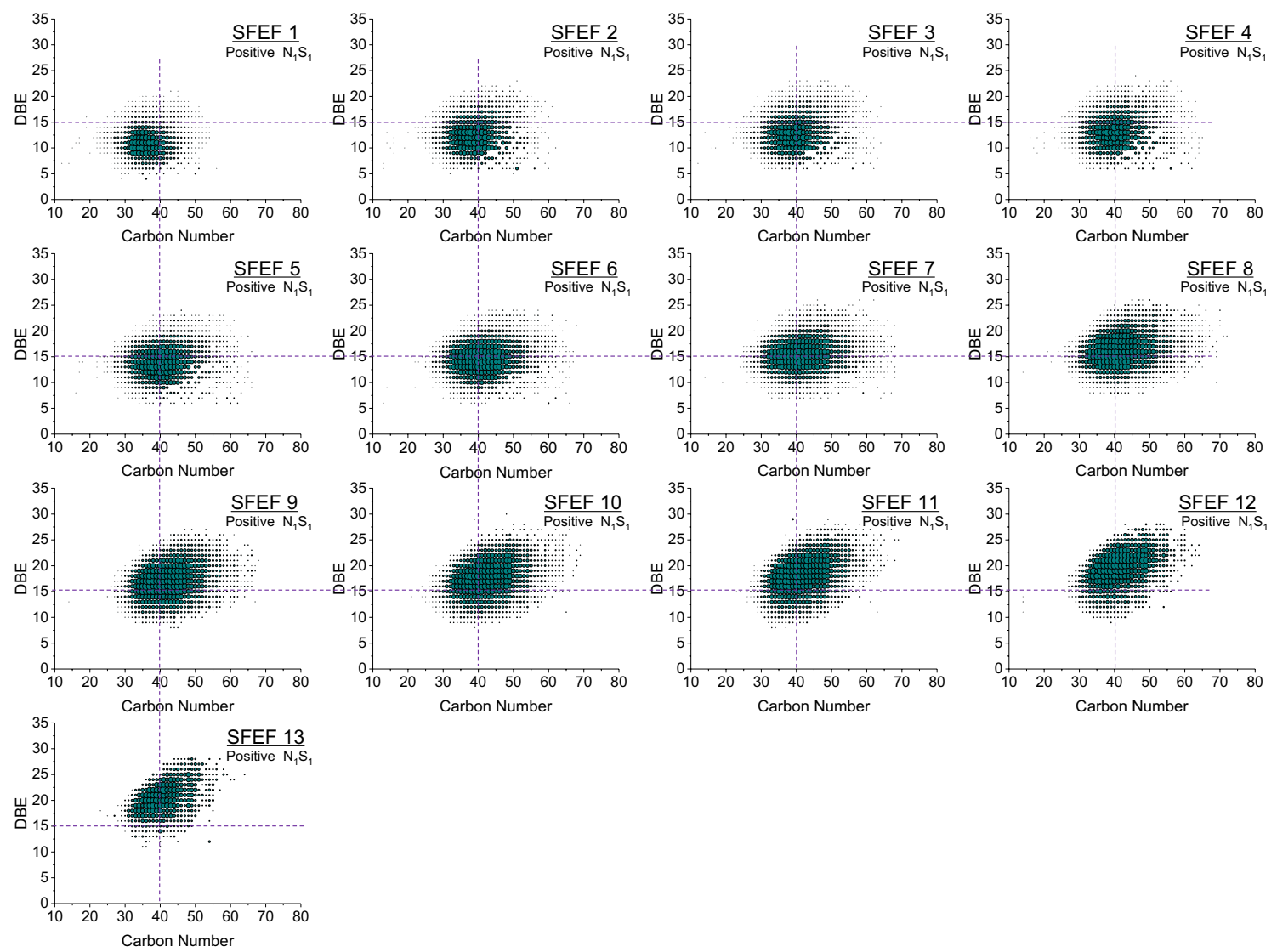

Fig. 10 Relative ion abundance plots of DBE as a function of carbon number derived from positive-ion ESI FT-ICR mass spectra for $\mathrm{N}_{1} \mathrm{~S}_{1}$-class species in various SFEF fractions. No $\mathrm{N}_{1} \mathrm{~S}_{1}$ compounds were detected in the end-cut

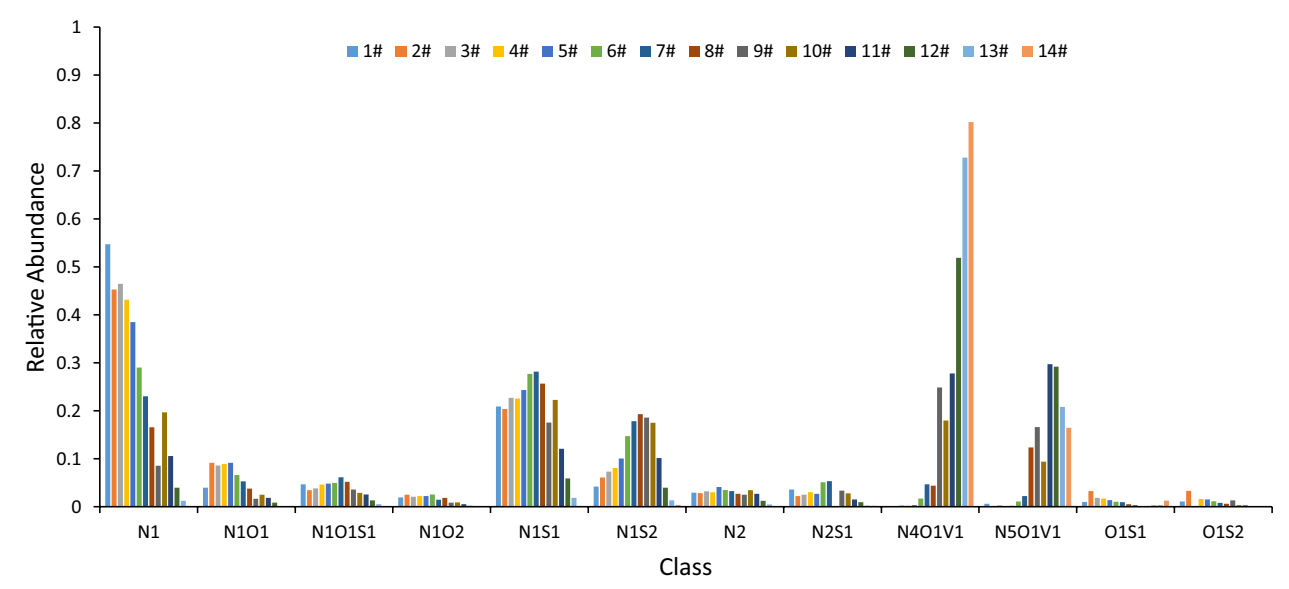

Fig. 11 Relative abundance of heteroatom class species assigned from positive-ion ESI FT-ICR mass spectra of various SFEF fractions

values for $\mathrm{O}_{2}$ class species among SFEF fractions showed a slight increase.

In general, the distributions of polar heteroatom species of oilsands bitumen-derived VR were similar to those of
Venezuela Orinoco extra heavy oil-derived VR; the carbon number and DBE gradually increased as the fraction became heavier. 


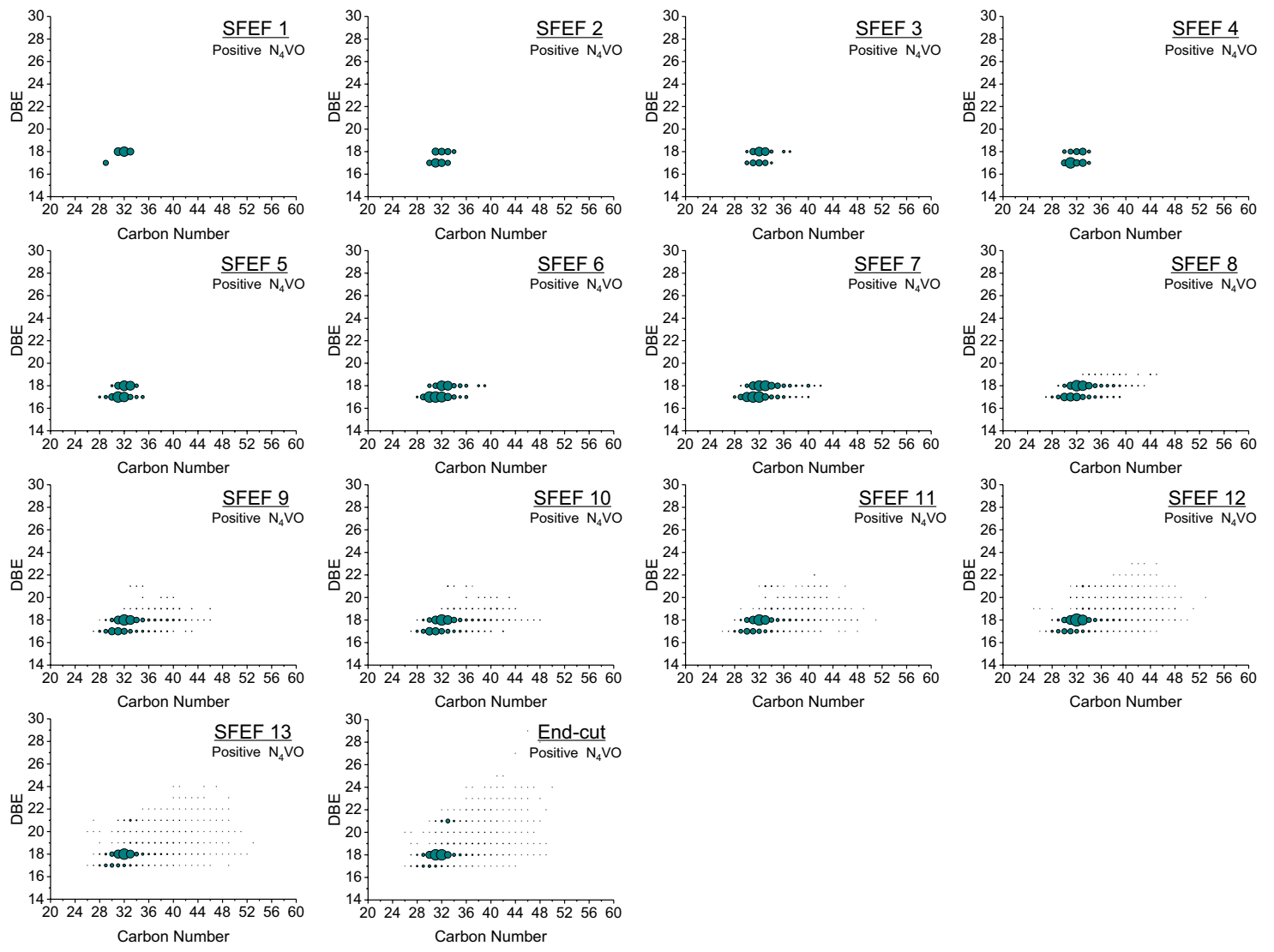

Fig. 12 Relative ion abundance plots of DBE as a function of carbon number for $\mathrm{N}_{4} \mathrm{VO}$ compounds in various SFEF fractions

\section{Conclusions}

Molecular composition of polar species in various SFEF fractions of a Canadian oilsands bitumen-derived VR was characterized using negative- and positive-ion ESI FT-ICR MS and compared to that of the Venezuela Orinoco extra heavy oilderived VR. The mass ranges of mass spectra and DBE value of polar heteroatom species increased as the SFEF fraction became heavier. The distributions of various class species were shifted as the SFEF fraction became heavier. The single functional compounds were dominant in the light SFEF fractions and the abundant multifunctional group compounds steadily increased as the SFEF fraction became heavier. The abundance of vanadyl porphyrins increased dramatically in heavy fractions, and accounted for $98 \%$ in the end-cut. The distributions of polar heteroatom species in the oilsands bitumen-derived VR were similar to those in the Venezuela Orinoco extra heavy oil-derived VR.

Open Access This article is distributed under the terms of the Creative Commons Attribution 4.0 International License (http://creativeco mmons.org/licenses/by/4.0/), which permits unrestricted use, distribution, and reproduction in any medium, provided you give appropriate credit to the original author(s) and the source, provide a link to the Creative Commons license, and indicate if changes were made.

\section{References}

Banerjee DK. Supercritical water processing of extra heavy crude in a slurry-phase up-flow reactor system. US7922895B2, April $12,2011$.

Chen Z, Liu J, Wu Y, et al. Polydisperse size distribution of monomers and aggregates of sulfur-containing compounds in petroleum residue fractions. Energy Fuels. 2015;29(8):4730-7. https ://doi.org/10.1021/acs.energyfuels.5b00418.

Cheng ZM, Ding Y, Zhao LQ, Yuan PQ, Yuan WK. Effects of supercritical water in vacuum residue upgrading. Energy Fuels. 2009;23(6):3178-83. https://doi.org/10.1021/ef900132z.

Chung KH, Xu C, Hu Y, Wang R. Supercritical fluid extraction reveals resid properties. Oil Gas J. 1997;95(3):66-9.

Demirbas A, Bafail A, Nizami AS. Heavy oil upgrading: unlocking the future fuel supply. Pet Sci Technol. 2016;34(4):303-8. https://doi. org/10.1080/10916466.2015.1136949.

Gao JS, Xu T, Wang G, Zhang AG, Xu CM. Reaction behavior of oil sand in fluidized-bed pyrolysis. Pet Sci. 2013;10(4):562-70. https ://doi.org/10.1007/s12182-013-0307-0.

Gulyaeva LA, Vinogradova NY, Khavkin VA, Bitiev GV. Refining unconventional types of crude oil stock by gasification. Chem Technol Fuels Oils. 2017;52(6):709-15. https://doi.org/10.1007/ s10553-017-0764-z.

Liu M, Wang M, Zhang L, et al. Transformation of sulfur compounds in the hydrotreatment of supercritical fluid extraction subfractions of Saudi Arabia atmospheric residua. Energy Fuels. 2015;29(2):70210. https://doi.org/10.1021/ef5025438. 
Morimoto M, Sugimoto Y, Saotome Y, Sato S, Takanohashi T. Effect of supercritical water on upgrading reaction of oil sand bitumen. J Supercrit Fluids. 2010;55(1):223-31. https://doi.org/10.1016/j. supflu.2010.08.002.

$\mathrm{Ng}$ SH, Al-Sabawi M, Wang JS, et al. FCC coprocessing oil sands heavy gas oil and canola oil. 1. Yield structure. Fuel. 2015;156:163-76. https://doi.org/10.1016/j.fuel.2015.03.077.

Ortega LC, Rogel E, Vien J, et al. Effect of precipitating conditions on asphaltene properties and aggregation. Energy Fuels. 2015;29(6):3664-74. https://doi.org/10.1021/acs.energyfuel s.5b00597.

Rodgers RP, Hendrickson CL, Emmett MR, et al. Molecular characterization of petroporphyrins in crude oil by electrospray ionization Fourier transform ion cyclotron resonance mass spectrometry. Can J Chem. 2001;79(5-6):546-51. https://doi.org/10.1139/v00-153.

Rose JL, Monnery WD, Chong K, Svrcek WY. Experimental data for the extraction of Peace River bitumen using supercritical ethane. Fuel. 2001;80(8):1101-10. https://doi.org/10.1016/s0016 -2361(00)00175-7.

Sato T, Mori S, Watanabe M, Sasaki M, Itoh N. Upgrading of bitumen with formic acid in supercritical water. J Supercrit Fluids. 2010;55(1):232-40. https://doi.org/10.1016/j.supflu.2010.07.010.

Scott DS, Radlein D, Piskorz J, Majerski P, Debruijn TJW. Upgrading of bitumen in supercritical fluids. Fuel. 2001;80(8):1087-99. https ://doi.org/10.1016/s0016-2361(00)00174-5.

Shi Q, Dong Z, Zhang Y, Zhao S, Xu C. Data processing of highresolution mass spectra for crude oil and its distillations. J Instrum Anal. 2008;27(1):246-8.

Shi Q, Pan N, Long H, et al. Characterization of middle-temperature gasification coal tar part 3: molecular composition of acidic compounds. Energy Fuels. 2013;27(1):108-17. https://doi. org/10.1021/ef301431y.

Subramanian M, Hanson FV. Supercritical fluid extraction of bitumens from Utah oil sands. Fuel Process Technol. 1998;55(1):35-53. https://doi.org/10.1016/s0378-3820(97)00076-3.

Wang S, Yang C, Xu C, Zhao S, Shi Q. Separation and characterization of petroleum asphaltene fractions by ESI FT-ICR MS and UV-vis spectrometer. Sci China Chem. 2013;56(7):856-62. https://doi. org/10.1007/s11426-013-4900-2.

Wei W, Yingrong L, Zelong L, Songbai T. Quantitative analysis using Fourier transform ion cyclotron resonance mass spectrometry and correlation between mass spectrometry data and sulfur content of crude oils. China Pet Proc Petrochem Technol. 2015;04:71-80.

Xu C, Hamilton S, Mallik A, Ghosh M. Upgrading of Athabasca Vacuum Tower Bottoms (VTB) in supercritical hydrocarbon solvents with activated carbon-supported metallic catalysts. Energy Fuels. 2007;21(6):3490-8. https://doi.org/10.1021/ef700459s.

Yahe Z, Hong L, Limin R, et al. Determination of unknown compound in aromatics by FT-ICR MS with various ionization techniques.
Acta Geol Sin (English Edition). 2015;S1:439. https://doi. org/10.1111/1755-6724.12307_13.

Yang G, Wang RA. The supercritical fluid extractive fractionation and the characterization of heavy oils and petroleum residua. $\mathrm{J}$ Pet Sci Eng. 1999;22(1-3):47-52. https://doi.org/10.1016/S0920 -4105(98)00056-4.

Yin PF, Liu GD, Liu YQ, Liu CL, Liu WP. Evaluation of oil sands resources-a case study in the Athabasca Oil Sands, NE Alberta, Canada. Pet Sci. 2013;10(1):30-7. https://doi.org/10.1007/s1218 2-013-0246-9.

Yuan B, Tang Z, Chung KH, et al. Asphaltenes extraction treatment yields advantaged hydroprocessing feedstock. Oil Gas J. 2016;114(6):70-5.

Zachariah A, de Klerk A. Partial upgrading of bitumen: impact of solvent deasphalting and visbreaking sequence. Energy Fuels. 2017;31(9):9374-80. https://doi.org/10.1021/acs.energyfuel s.7b02004.

Zaikin YA, Zaikina RF. Upgrading and refining of crude oils and petroleum products by ionizing irradiation. Top Curr Chem. 2016;374(3):32. https://doi.org/10.1007/s41061-016-0035-1.

Zhang L, Xu Z, Shi Q, et al. Molecular characterization of polar heteroatom species in Venezuela Orinoco petroleum vacuum residue and its supercritical fluid extraction subfractions. Energy Fuels. 2012a;26(9):5795-803. https://doi.org/10.1021/ef3009663.

Zhang L, Xu Z, Shi Q, et al. Molecular characterization of polar heteroatom species in Venezuela Orinoco petroleum vacuum residue and its supercritical fluid extraction subfractions. Energy Fuels. 2012b;26(9):5795-803. https://doi.org/10.1021/ef3009663.

Zhang L, Zhao S, Xu Z, et al. Molecular weight and aggregation of heavy petroleum fractions measured by vapor pressure osmometry and a hindered stepwise aggregation model. Energy Fuels. 2014;28(10):6179-87. https://doi.org/10.1021/ef500749d.

Zhang T, Zhang L, Zhou Y, et al. Transformation of nitrogen compounds in deasphalted oil hydrotreating: characterized by electrospray ionization Fourier transform-ion cyclotron resonance mass spectrometry. Energy Fuels. 2013;27(6):2952-9. https:// doi.org/10.1021/ef400154u.

Zhang YM, Huang L, Zhang XC, et al. Upgrading of Canadian oil sand bitumen via cracking and coke gasification: effect of catalyst and operating parameters. Energy Fuels. 2017;31(7):7438-44. https ://doi.org/10.1021/acs.energyfuels.7b01087.

Zhao S, Zhang L, Chen Z, et al. The chemical fundamentals for heavy oil supercritical fluid extraction and multi-stage separation technology. Sci Sin Chim (Chinese Edition). 2018;48(4):369-86. https ://doi.org/10.1360/n032017-00165.

Zhou S, Huang H, Liu Y. Biodegradation and origin of oil sands in the Western Canada Sedimentary Basin. Pet Sci. 2008;5(2):87-94. https://doi.org/10.1007/s12182-008-0015-3. 